\title{
Comparison of Direct-Drive and Geared Generator Concepts for Wind Turbines
}

\author{
Henk Polinder, Member, IEEE, Frank F. A. van der Pijl, Gert-Jan de Vilder, and Peter J. Tavner
}

\begin{abstract}
The objective of this paper is to compare five different generator systems for wind turbines, namely the doubly-fed induction generator with three-stage gearbox (DFIG3G), the directdrive synchronous generator with electrical excitation (DDSG), the direct-drive permanent-megnet generator (DDPMG), the permanent-magnet generator with single stage gearbox (PMG1G), and the doubly-fed induction generator with single-stage gearbox (DFIG1G). The comparison is based on cost and annual energy yield for a given wind climate. The DFIG3G is a cheap solution using standard components. The DFIG1G seems the most attractive in terms of energy yield divided by cost. The DDPMG has the highest energy yield, but although it is cheaper than the DDSG, it is more expensive than the generator systems with gearbox.
\end{abstract}

Index Terms-Direct-drive, doubly fed induction generator (DFIG), permanent-magnet generator, single-stage gearbox, synchronous generator, wind turbine.

\section{INTRODUCTION}

$\mathbf{T}$ HE objective of this paper is to compare five different generator systems for wind turbines, namely the doublyfed induction generator with three-stage gearbox (DFIG3G), the direct-drive synchronous generator with electrical excitation (DDSG), the direct-drive permanent-magnet generator (DDPMG), the permanet-magnet generator with single stage gearbox (PMG1G) and the doubly-fed induction generator with single-stage gearbox (DFIG1G).

The three most commonly used generator systems for wind turbines are as follows [1], [2].

1) Until the late 1990s, most wind turbine manufacturers built constant-speed wind turbines with power levels below 1.5 MW using a multistage gearbox and a standard squirrel-cage induction generator, directly connected to the grid.

2) Since the late 1990s, most wind turbine manufacturers have changed to variable speed wind turbines for power levels from roughly $1.5 \mathrm{MW}$, mainly to enable a more flexible match with requirements considering audible noise, power quality, and energy yield. They have used a multistage gearbox, a relatively low-cost standard DFIG and a

Manuscript received May 25, 2005; revised January 30, 2006. This work was supported in part by Zephyros BV, Hilversum, The Netherlands and in part by ATO Maritiem Platform, Den Helder, The Netherlands. Paper no. TEC-001762005.

H. Polinder and F. F. A. van der Pijl are with the Electrical Power Processing Group of Delft University of Technology, 2628CD Delft, The Netherlands. They are also with DUWIND, the Interfaculty Delft University Wind Energy Research Institute (e-mail: h.polinder@tudelft.nl; f.vanderpijl@tudelft.nl).

G.-J. de Vilder is with Harakosan Europe BV, 1213 NS Hilversum, The Netherlands (e-mail: g.de.vilder@harakosan.nl).

P. J. Tavner is with the School of Engineering, Durham University, Durham DH1 3LE, U.K. (e-mail: peter.tavner@durham.ac.uk).

Digital Object Identifier 10.1109/TEC.2006.875476

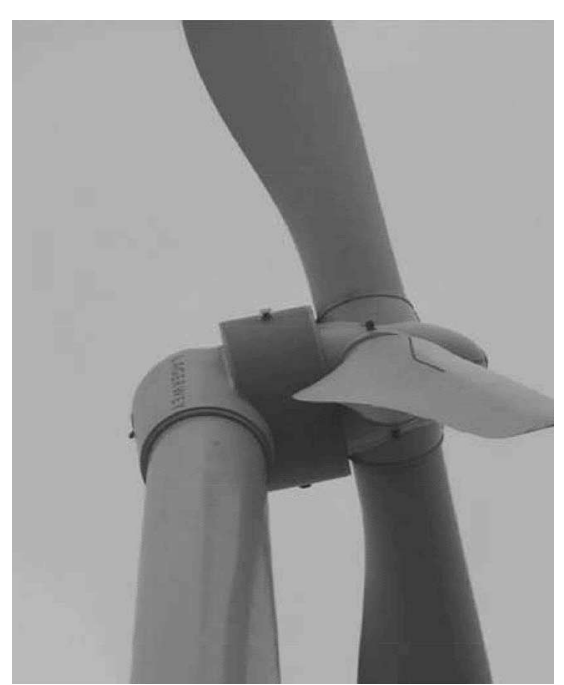

Fig. 1. Photo of a 1.5-MW direct-drive wind turbine with permanent-magnet generator of Zephyros. Source: Zephyros BV.

power electronic converter feeding the rotor winding with a power rating of approximately $30 \%$ of the rated power of the turbine.

3) Since 1991, there have also been wind turbine manufacturers proposing gearless generator systems with the socalled direct-drive generators, mainly to reduce failures in gearboxes and to lower maintenance problems. A power electronic converter for the full-rated power is then necessary for the grid connection. The low-speed high-torque generators and the fully rated converters for these wind turbines are rather expensive.

Most direct-drive turbines being sold at the moment have synchronous generators with electrical excitation. However, [3]-[7] claim benefits for permanent magnet excitation, which eliminates the excitation losses. In this paper, this difference is quantified. Fig. 1 depicts an example of a wind turbine with a permanent-magnet direct-drive generator [8].

For the increasing power levels and decreasing speeds, these direct-drive generators are becoming larger and even more expensive. Therefore, it has been proposed to use a single-stage gearbox (with a gear ratio in the order of 6 or higher) and a permanent-magnet generator [7]. This system, called the multibrid system, is illustrated in Fig. 2.

On the one hand, the resulting system combines some of the disadvantages of both the geared and direct-drive systems: the system has a gearbox and it has a special and therefore expensive generator and a fully rated converter. On the other hand, compared to direct-drive systems, a significant decrease 


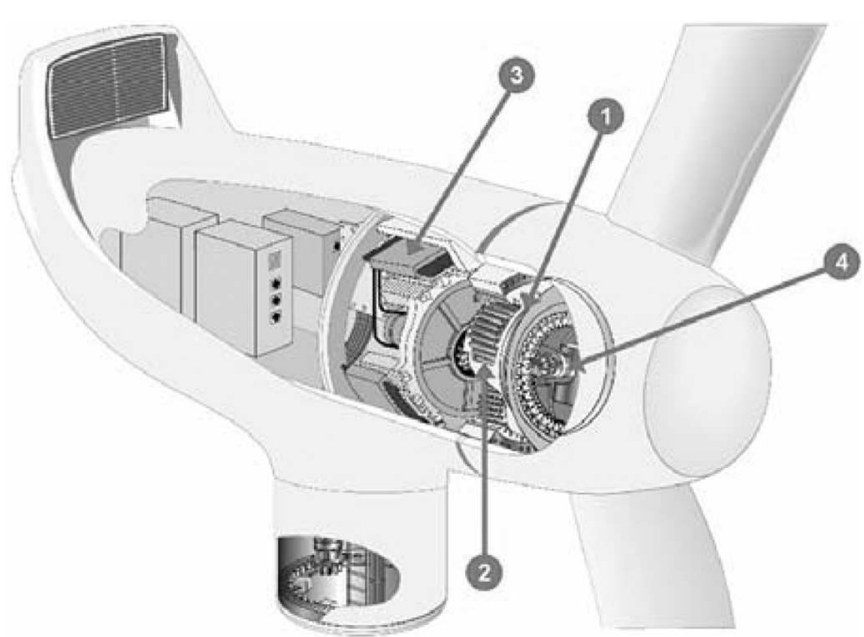

The rotor is combined to the power unit using a custom-made throe-row roller bearing (1). The roller bearing transfers the rotor loads directly to the main casing past the planetary gea and generator.

The single-stage planetary goar (2) increases the rotating speed from 8-25 rpm to 44-146 rpm.

The low speed permanent magnet generator (3) produces the electricity.
The rotational speed of rotor is controlled by three independent electric pitches (4).

Fig. 2. Sketch of the system with a single-stage gearbox. Source: WinWinD.

in the generator cost and an increase in the generator efficiency can be obtained.

Further, the question arises whether this system with a singlestage gearbox could be used in combination with a DFIG. Because the generator torque is still rather high and the speed rather low, the generator can be expected to have a large diameter and air gap, and therefore a high magnetizing current and high losses. However, the rating of the converter could be reduced to roughly $30 \%$, giving an important benefit in cost and efficiency. This new system is introduced and further investigated in this paper.

For both systems with a single-stage gearbox, the use of a gearbox leads to a significant reduction of the external dimensions, enabling the installation of such a $3-\mathrm{MW}$ wind turbine on locations that are currently limited from a logistic point of view to $1.5-\mathrm{MW}$ turbines.

The objective of this paper, therefore, is to compare five wind turbine generator systems, namely:

1) the DFIG3G as currently used;

2) the DDSG as currently used;

3) the DDPMG;

4) the PMG1G;

5) the DFIG1G.

To compare the five generator systems, a 3-MW, 15-r/min wind turbine is used. For this turbine, an approximate design of the generators is made to get indications of weight and cost. The differences in annual energy yield are calculated for a given wind climate. This comparison and the proposal to use a DFIG in combination with a single-stage gearbox are the original contributions of this paper.

An early comparison of the efficiency of three wind turbine generator systems is given in [9]. In [6] and [7], more generator systems were compared and more criteria were taken into account. The contribution of this paper is that it introduces the
TABLE I

MODELING CHARACTERISTICS

\begin{tabular}{|c|c|}
\hline \multicolumn{2}{|l|}{ Wind turbine characteristics } \\
\hline Rated grid power (MW) & 3 \\
\hline Rotor diameter $(\mathrm{m})$ & 90 \\
\hline Rated wind speed (m/s) & 12 \\
\hline Rated speed (rpm) & 15 \\
\hline Optimum tip speed ratio (blade tip speed divided by wind speed) & 8 \\
\hline Maximum aerodynamic rotor efficiency (\%) & 48 \\
\hline Mass density of air $\left(\mathrm{kg} / \mathrm{m}^{3}\right)$ & 1.225 \\
\hline \multicolumn{2}{|l|}{ Generator material characteristics } \\
\hline Slot filling factor $k_{s f i l}$ & 0.6 \\
\hline Remanent flux density of the magnets $B_{r m}(\mathrm{~T})$ & 1.2 \\
\hline Recoil permeability of the magnets $\mu_{r m}$ & 1.06 \\
\hline Resistivity of copper at $120^{\circ} \rho_{C u}(\mu \Omega \mathrm{m})$ & 0.025 \\
\hline Eddy-current losses in laminations at $1.5 \mathrm{~T}$ and $50 \mathrm{~Hz} P_{\mathrm{FeOe}}(\mathrm{W} / \mathrm{kg})$ & 0.5 \\
\hline Hysteresis losses in laminations at $1.5 \mathrm{~T}$ and $50 \mathrm{~Hz} P_{\mathrm{Fe} e h}(\mathrm{~W} / \mathrm{kg})$ & 2 \\
\hline \multicolumn{2}{|l|}{ Loss modeling } \\
\hline Maximum losses in a single-stage gearbox $P_{\text {gearm }}(\mathrm{kW})$ & 45 \\
\hline Maximum losses in a three-stage gearbox $P_{\text {gearm }}(\mathrm{kW})$ & 90 \\
\hline Maximum losses in a 3 MW VSI $P_{\text {convm }}(\mathrm{kW})$ & 90 \\
\hline Maximum losses in a 1 MW VSI $P_{\text {convm }}(\mathrm{kW})$ & 30 \\
\hline \multicolumn{2}{|l|}{ Cost modeling } \\
\hline Single-stage gearbox (ratio 6) cost (kEuro) & 120 \\
\hline Three-stage gearbox (ratio 80) cost (kEuro) & 220 \\
\hline Power electronics cost (Euro/kW) & 40 \\
\hline Laminations cost (Euro/kg) & 3 \\
\hline Copper cost (Euro/kg) & 15 \\
\hline Permanent magnet cost (Euro/kg) & 25 \\
\hline Rest of wind turbine cost (kEuro) & 1300 \\
\hline Margin for company profit (kEuro) & 250 \\
\hline
\end{tabular}

DFIG1G, and compares it with four other generator systems. It also quantifies the difference between the electrical-excited direct-drive generator and the PM direct-drive generator.

The paper starts with a section about modeling of the wind turbine, the gearbox, the converter, and the generator. Next the five generator designs are briefly described and the resulting performance is given. The paper concludes with a comparison of the five generator concepts.

\section{MODEling THE GENERATOR CONCEPTS}

\section{A. Wind Turbine Modeling}

Table I gives the characteristics of the wind turbine that was used to compare the different generator systems. Using these characteristics, the available shaft power $P$ can be calculated as a function of the wind speed as [2], [10]

$$
P=\frac{1}{2} \rho_{\text {air }} C_{\mathrm{p}}(\lambda, \theta) \pi r^{2} v_{\mathrm{w}}^{3}
$$

where $\rho_{\text {air }}$ is the mass density of air, $r$ is the wind turbine rotor radius, $v_{\mathrm{w}}$ is the wind speed, and $C_{\mathrm{p}}(\lambda, \theta)$ is the power coefficient or the aerodynamic efficiency, which is a function of the tip speed ratio $\lambda$ (tip speed divided by wind speed) and the pitch angle $\theta$.

Fig. 3 illustrates the rotor speed, which is assumed to be proportional to the wind speed at maximum aerodynamic efficiency at low wind speeds and equal to the rated rotor speed at higher wind speeds (above $9 \mathrm{~m} / \mathrm{s}$ ). At wind speeds above the rated 

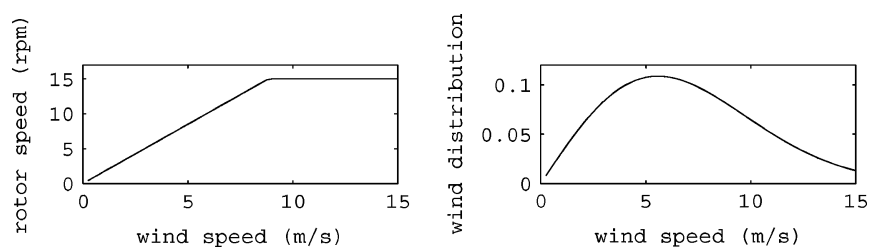

Fig. 3. Rotor speed and Weibull distribution of the wind as a function of wind speed.

wind speed, the blades are pitched to reduce the aerodynamic efficiency and so the power.

For energy yield calculations, an average wind speed of $7 \mathrm{~m} / \mathrm{s}$ with a Weibull distribution [10] is used as illustrated in Fig. 3. Integrating the area below the curve gives a value of 1 .

Table I also gives some approximate numbers for the cost of the rest of the wind turbine. Because the paper concentrates on the generator system, these numbers are not extensively validated and must be seen only as indicators.

\section{B. Gearbox Modeling}

The gear ratio of the single-stage gearbox is chosen as 6 . Some references suggest higher gear ratios [7]. However, at the moment, this is not seen as proven technology with a guaranteed lifetime. From the commercially available gearboxes, it appears to be cheaper to use gearboxes with more stages for higher gear ratios. A cost estimate of the gearbox is given in Table $\mathrm{I}$.

According to [11], a viscous loss of $1 \%$ of the rated power per gearbox stage is a reasonable model. This means that the losses are proportional to the speed

$$
P_{\text {gear }}=P_{\text {gearm }} \frac{n}{n_{\text {rated }}}
$$

where $P_{\text {gearm }}$ is the loss in the gearbox at rated speed (3\% of rated power for a three-stage gearbox [11] and $1.5 \%$ for a single-stage gearbox, see Table I), $n$ is the rotor speed $(\mathrm{r} / \mathrm{min})$, and $n_{\text {rated }}$ is the rated rotor speed $(\mathrm{r} / \mathrm{min})$.

\section{Converter Modeling}

A back-to-back voltage source inverter is used to ensure that the generator currents and the grid currents are sinusoidal. A cost estimate is given in Table I.

There are various ways of modeling converter losses [12]. The model used here divides them into three parts [13]:

1) a small part that is constant and consists of power dissipated in power supplies, gate drivers, control, cooling systems and so on [9];

2) a large part that is proportional to the current and consists of switching losses and conduction losses;

3) a part that is proportional to the current squared and consists of conduction losses because the on-state voltage of a semiconductor increases with the current.

Therefore, the losses in the converter $P_{\text {conv }}$ are modeled as

$$
P_{\text {conv }}=\frac{P_{\text {convm }}}{31}\left(1+10 \frac{I_{\mathrm{s}}}{I_{\mathrm{sm}}}+5 \frac{I_{\mathrm{s}}^{2}}{I_{\mathrm{sm}}^{2}}+10 \frac{I_{\mathrm{g}}}{I_{\mathrm{gm}}}+5 \frac{I_{\mathrm{g}}^{2}}{I_{\mathrm{gm}}^{2}}\right)
$$

where $P_{\text {convm }}$ is the dissipation in the converter at rated power ( $3 \%$ of the rated power of the converter, see Table I), $I_{\mathrm{s}}$ is the generator side converter current, $I_{\mathrm{sm}}$ is the maximum generator side converter current, $I_{\mathrm{g}}$ is the grid side converter current, and $I_{\mathrm{gm}}$ is the maximum grid side converter current.

\section{Generator Modeling}

The different generators are modeled using equivalent circuit models. This section describes the equations used to determine the parameters of the equivalent circuit. The machine parameters are calculated in conventional ways [9].

The following assumptions are used in the calculations.

1) Space harmonics of the magnetic flux density distribution in the air gap are negligible; only the fundamental is considered.

2) The magnetic flux density crosses the air-gap perpendicularly.

Slot, air-gap, and end-winding leakage inductances are calculated as given in [14]. The magnetizing inductance of an AC machine is given by [14], [15]

$$
L_{\mathrm{sm}}=\frac{6 \mu_{0} l_{\mathrm{s}} r_{\mathrm{s}}\left(k_{\mathrm{w}} N_{\mathrm{s}}\right)^{2}}{p^{2} g_{\mathrm{eff}} \pi}
$$

where $l_{\mathrm{s}}$ is the stack length in axial direction, $r_{\mathrm{s}}$ is the stator radius, $N_{\mathrm{s}}$ is the number of turns of the phase winding, $k_{\mathrm{w}}$ is the winding factor [14], [15], $p$ is the number of pole pairs, and $g_{\text {eff }}$ is the effective air gap.

The effective air gap of the machine depends on the type of machine. For all machine types, it can be written as

$$
g_{\mathrm{eff}}=k_{\mathrm{sat}} k_{\mathrm{Cs}} k_{\mathrm{Cr}}\left(g+\frac{l_{\mathrm{m}}}{\mu_{\mathrm{rm}}}\right)
$$

where $k_{\text {sat }}$ is a factor representing the reluctance of the iron in the magnetic circuit, $k_{\mathrm{Cs}}$ is the Carter factor for the stator slots [14], $k_{\mathrm{Cr}}$ is the Carter factor for the rotor slots (if present) [14], $g$ is the mechanical air gap, $\mu_{\mathrm{rm}}$ is the relative recoil permeability of the magnets, and $l_{\mathrm{m}}$ is the magnet length in the direction of the magnetization (which is zero in a machine without permanent magnets).

The Carter factor is given by [14], [16]

$$
\begin{aligned}
k_{\mathrm{C}} & =\frac{\tau_{\mathrm{s}}}{\tau_{\mathrm{s}}-g_{1} \gamma} \\
g_{1} & =g+\frac{l_{\mathrm{m}}}{\mu_{\mathrm{rm}}} \\
\gamma & =\frac{4}{\pi}\left(\frac{b_{\mathrm{so}}}{2 g_{1}} \arctan \left(\frac{b_{\mathrm{so}}}{2 g_{1}}\right)-\log \sqrt{1+\left(\frac{b_{\mathrm{so}}}{2 g_{1}}\right)^{2}}\right)
\end{aligned}
$$

where $\tau_{\mathrm{S}}$ is the slot pitch and $b_{\mathrm{so}}$ is the slot opening width.

The factor representing the reluctance of the iron of the magnetic circuit is calculated as [17]

$$
k_{\mathrm{sat}}=1+\frac{1}{H_{\mathrm{g}} g_{\mathrm{eff}}} \int_{0}^{l_{\mathrm{Fe}}} H_{\mathrm{Fe}} d l_{\mathrm{Fe}}
$$

where $H_{\mathrm{Fe}}$ is the magnetic field intensity in the iron, estimated from the $\mathrm{BH}$ curve. 


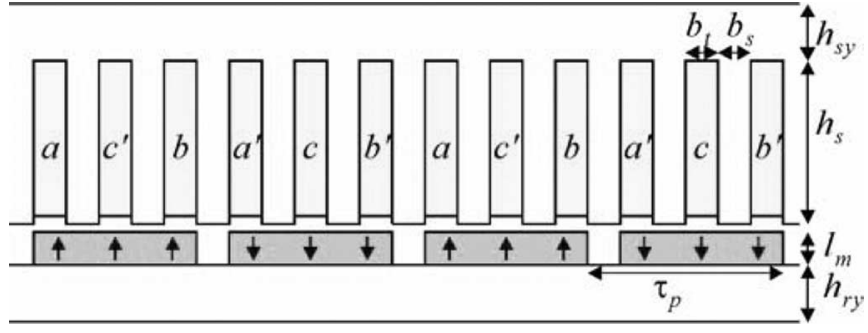

Fig. 4. Sketch of a cross section of four poles of a permanent magnet synchronous machine with full pitch winding.

In permanent-magnet machines, this factor representing saturation is much smaller than in the other machines because the effective air gap is much larger due to the low permeability of the magnets.

Using Ampere's circuital law, the BH characteristic of a rareearth permanent magnet and the magnetic flux continuity, the flux density above a magnet in the air gap of a permanent-magnet machine (Fig. 4) can be calculated as [15]

$$
\hat{B}_{\mathrm{g}}=\frac{l_{\mathrm{m}}}{\mu_{\mathrm{rm}} g_{\mathrm{eff}}} B_{\mathrm{rm}}
$$

where $B_{\mathrm{rm}}$ is the remanent flux density of the magnets $(1.2 \mathrm{~T})$.

Using Fourier analysis, the fundamental space harmonic of this flux density can be calculated as [15], [16]

$$
\hat{B}_{\mathrm{g}}=\frac{l_{\mathrm{m}}}{\mu_{\mathrm{rm}} g_{\mathrm{eff}}} B_{\mathrm{rm}} \frac{4}{\pi} \sin \left(\frac{\pi b_{\mathrm{p}}}{2 \tau_{\mathrm{p}}}\right)
$$

where $\tau_{\mathrm{p}}$ is the pole pitch and $b_{\mathrm{p}}$ is the width of the magnet.

The no-load (motional) voltage induced by this flux density in a stator winding can be calculated as [15], [16]

$$
E_{\mathrm{p}}=\sqrt{2} k_{\mathrm{w}} N_{\mathrm{s}} \omega_{\mathrm{m}} r_{\mathrm{s}} l_{\mathrm{s}} \hat{B}_{\mathrm{g}}
$$

where $\omega_{\mathrm{m}}$ is the mechanical angular speed of the rotor.

The copper losses are calculated from the currents and the resistances. The phase resistance is calculated as

$$
R_{\mathrm{s}}=\frac{\rho_{\mathrm{Cu}} l_{\mathrm{Cus}}}{A_{\mathrm{Cus}}}
$$

where $\rho_{\mathrm{Cu}}$ is the resistivity of copper, $A_{\mathrm{Cus}}$ is the cross-sectional area of the conductor, and $l_{\mathrm{Cus}}$ is the length of the conductor of the phase winding.

The length of the conductor is calculated as the number of turns multiplied by the length of a turn, where the length of a turn is estimated as twice stack length (in the slots) plus four times the pole pitch (for the end windings)

$$
l_{\text {Cus }}=N_{\mathrm{s}}\left(2 l_{\mathrm{s}}+4 \tau_{\mathrm{p}}\right) \text {. }
$$

The cross-section area of the conductor is the available slot area multiplied by the fill factor divided by the number of turns per slot:

$$
A_{\mathrm{Cus}}=\frac{p q k_{\mathrm{sfil}} b_{\mathrm{sav}} h_{\mathrm{s}}}{N_{\mathrm{s}}}
$$

where $q$ is the number of slots per pole per phase, $k_{\text {sfil }}$ is the slot fill factor $(60 \%), b_{\mathrm{sav}}$ is the average slot width, and $h_{\mathrm{s}}$ is the slot height.
The specific iron losses (the iron losses per unit mass) are calculated using [14], [15]

$$
\begin{aligned}
P_{\mathrm{Fe}}=2 P_{\mathrm{Fe} 0 \mathrm{~h}}\left(\frac{f_{\mathrm{e}}}{f_{0}}\right)\left(\frac{\hat{B}_{\mathrm{Fe}}}{\hat{B}_{0}}\right)^{2} & \\
& +2 P_{\mathrm{Fe} 0 \mathrm{e}}\left(\frac{f_{\mathrm{e}}}{f_{0}}\right)^{2}\left(\frac{\hat{B}_{\mathrm{Fe}}}{\hat{B}_{0}}\right)^{2}
\end{aligned}
$$

where $f_{\mathrm{e}}$ is the frequency of the field in the iron, $P_{\mathrm{Fe} 0 \mathrm{~h}}$ is the hysteresis loss per unit mass at the given angular frequency $f_{0}$ and flux density $B_{0}$ (Table I), and $P_{\mathrm{Fe} 0 \mathrm{e}}$ is the eddy current loss per unit mass at the given angular frequency $f_{0}$ and flux density $B_{0}$ (Table I).

The factor 2 is included in this equation because the flux densities do not change sinusoidally and they are not sinusoidally distributed, which increases the iron losses. High quality laminations are used to limit the iron losses in the generators with higher frequencies.

To calculate the total iron losses, the specific iron losses in the different parts (teeth and yokes) are evaluated, multiplied by the weight of these parts, and added.

To find out the cost of a generator, the masses of iron, copper, and magnets are calculated and multiplied by the assumed cost per kilogram of the material (see Table I).

\section{Generator Design And Performance}

\section{A. DFIG3G}

The number of pole pairs of the DFIG3G is chosen as 3 . Because the stator is directly connected to the $50-\mathrm{Hz}$ grid, the synchronous speed is $1000 \mathrm{r} / \mathrm{min}$. With a gear ratio of 80 , the rated speed of the generator is $1200 \mathrm{r} / \mathrm{min}$, so that at rated speed, there is still some margin for control purposes.

The DFIG3G has an air-gap radius of $0.42 \mathrm{~m}$ and a stack length of $0.75 \mathrm{~m}$. Other important dimensions are given in Table II.

Fig. 5 depicts two induction-machine equivalent circuits. The rotor side parameters are all referred parameters. The parameters of the second equivalent circuit can be calculated from the parameters of the first in the following way [15]:

$$
\begin{aligned}
& L_{\mathrm{s}}=L_{\mathrm{s} \sigma}+L_{\mathrm{sm}} ; \\
& R_{\mathrm{R}}=\frac{R_{\mathrm{r}} L_{\mathrm{s}}^{2}}{L_{\mathrm{sm}}^{2}} \\
& L_{\mathrm{L}}=\frac{L_{\mathrm{s} \sigma} L_{\mathrm{s}}}{L_{\mathrm{sm}}}+\frac{L_{\mathrm{r} \sigma} L_{s}^{2}}{L_{\mathrm{sm}}^{2}} .
\end{aligned}
$$

To simplify the calculations, the second equivalent circuit has been used. It is further assumed that the converter controls the rotor current in such a way that the magnetizing current is confined to the stator and that the transformed rotor current $I_{\mathrm{R}}$ is in phase with the voltage applied to the inductance $L_{\mathrm{s}}$.

Fig. 6 depicts some results from the model as a function of the wind speed. Voltage, current, power, generator efficiency, generator system efficiency (including losses in the converter and the gearbox), and losses are depicted. The annual energy 
TABLE II

Main Dimensions, Parameters, Weights, Cost, AND ANNUAL ENERGY OF THE FIVE GENERATOR SYSTEMS

\begin{tabular}{|c|c|c|c|c|c|}
\hline & \begin{tabular}{r|} 
DFIG \\
$3 \mathrm{G}$ \\
\end{tabular} & \begin{tabular}{|l}
$\mathrm{DD}$ \\
$\mathrm{SG}$ \\
\end{tabular} & $\begin{array}{r}\text { DD } \\
\text { PMG } \\
\end{array}$ & $\begin{array}{r}\mathrm{PMG} \\
1 \mathrm{G} \\
\end{array}$ & $\begin{array}{r}\text { DFIG } \\
1 \mathrm{G} \\
\end{array}$ \\
\hline \multicolumn{6}{|c|}{ Generator dimensions } \\
\hline Stator radius $r_{s}(\mathrm{~m})$ & 0.42 & 2.5 & 2.5 & 1.8 & 1.8 \\
\hline Stack length $l_{s}(\mathrm{~m})$ & 0.75 & 1.2 & 1.2 & 0.4 & 0.6 \\
\hline Number of pole pairs $p$ & 3 & 40 & 80 & 56 & 40 \\
\hline Number of slots per pole per phase $q$ & 6 & 2 & 1 & 1 & \\
\hline Air gap $g(\mathrm{~mm})$ & 1 & 5 & 5 & 3.6 & \\
\hline Stator slot width $b_{S S}(\mathrm{~mm})$ & 12.9 & 15 & 15 & 15 & 11 \\
\hline Stator tooth width $b_{s t}(\mathrm{~mm})$ & 11.5 & 18 & 18 & 19 & 12.5 \\
\hline Stator slot height $h_{s s}(\mathrm{~mm})$ & 60 & 80 & 80 & 80 & 60 \\
\hline Stator yoke height $h_{s y}(\mathrm{~mm})$ & 100 & 60 & 40 & 40 & 50 \\
\hline Rotor slot width $b_{r s}(\mathrm{~mm})$ & 10 & - & - & - & 10 \\
\hline Rotor tooth width $b_{r t}(\mathrm{n}$ & 11.5 & - & - & - & 12. \\
\hline Rotor slot height $h_{r s}(\mathrm{~mm})$ & 60 & - & - & - & 6 \\
\hline Rotor yoke height $h_{r y}(\mathrm{~mm})$ & 100 & 60 & 40 & 40 & 50 \\
\hline Pole/magnet height $h_{p} / l_{m}(\mathrm{~mm})$ & - & 140 & 15 & 15 & \\
\hline Rotor pole width $b_{p}(\mathrm{~mm})$ & - & 137 & 79 & 82 & \\
\hline \multicolumn{6}{|c|}{ Generator parameters } \\
\hline Main inductance $L_{m}(\mathrm{mH})$ & 99 & 46 & 4 & 0.88 & 17 \\
\hline Stator leakage induct. $L_{s \sigma}(\mathrm{mH})$ & 0.99 & 8.2 & 7.3 & 1.4 & 1.7 \\
\hline Stator $\mathrm{r}$ & 26 & 119 & 88 & 22 & 4 \\
\hline Rotor leakage induct. $L_{r \sigma}(\mathrm{mH})$ & 1.2 & - & - & - & 1.8 \\
\hline Rotor resistance $R_{r}(\mathrm{~m} \Omega)$ & 35 & & 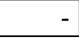 & & 48 \\
\hline \multicolumn{6}{|c|}{ Generator material weight (ton) } \\
\hline Iron (tol & 4.03 & 32.5 & 18.1 & 4.37 & 8.65 \\
\hline Cop & 1.21 & 12.6 & 4.3 & 1.33 & 2.72 \\
\hline PM (ton) & -1 & - & 1.7 & 0.41 & \\
\hline Total (ton) & 5.25 & 45.1 & 24.1 & 6.11 & 11.37 \\
\hline \multicolumn{6}{|c|}{ Cost (kEuro) } \\
\hline Gener: & 30 & 287 & 162 & 43 & 67 \\
\hline Generator & 30 & 160 & 150 & 50 & 60 \\
\hline Gearbox & 220 & - & - & 120 & 120 \\
\hline Converter & 40 & 120 & 120 & 120 & 40 \\
\hline Generator system cost & 320 & 567 & 432 & 333 & 287 \\
\hline Other wind turbine parts appr. & 1300 & 1300 & 1300 & 1300 & 1300 \\
\hline Margin for company costs & 250 & 250 & 250 & 250 & 250 \\
\hline Total cost & 1870 & 2117 & 1982 & 1883 & 1837 \\
\hline \multicolumn{6}{|c|}{ Annual energy } \\
\hline Copper losses (MWh) & 82 & 456 & 189 & 48 & 232 \\
\hline Iron losses (MWh) & 70 & 40 & 89 & 123 & 123 \\
\hline Converter losses (MWh) & 78 & 243 & 235 & 232 & 79 \\
\hline Gearbox losses (MWh) & 533 & -1 & - & 273 & 267 \\
\hline Total losses (MWh) & 763 & 739 & 513 & 674 & 701 \\
\hline Energy yield (GWh) & 7.73 & 7.88 & 8.04 & 7.84 & 7.80 \\
\hline \multicolumn{6}{|c|}{ Annual energy yield / total cost } \\
\hline (kWh/Euro) & \begin{tabular}{|l|}
4.13 \\
\end{tabular} & 3.72 & 4.05 & 4.16 & 4.2 \\
\hline
\end{tabular}

dissipation, determined from a combination of the losses with the Weibull distribution, is also depicted in Fig. 6. Table II gives the annual energy yield and the annual dissipation. It also gives cost estimates.

The losses in the gearbox dominate the losses in this generator system: Roughly $70 \%$ of the annual energy dissipation in the generator system is in the gearbox.

\section{B. DDSG}

The air-gap diameter of the DDSG is chosen to be $5 \mathrm{~m}$. From the electromagnetic point of view, larger air-gap diameters are better, but mechanical design, construction and transportation
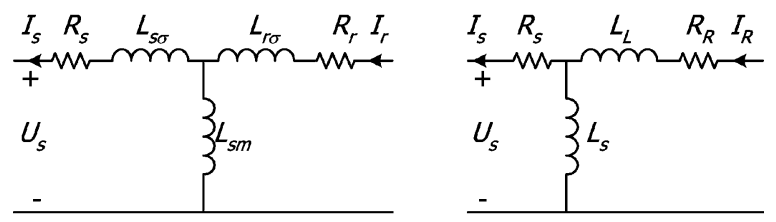

Fig. 5. IEEE recommended equivalent circuit of the induction machine and the applied $\Gamma$-type equivalent circuit [15].
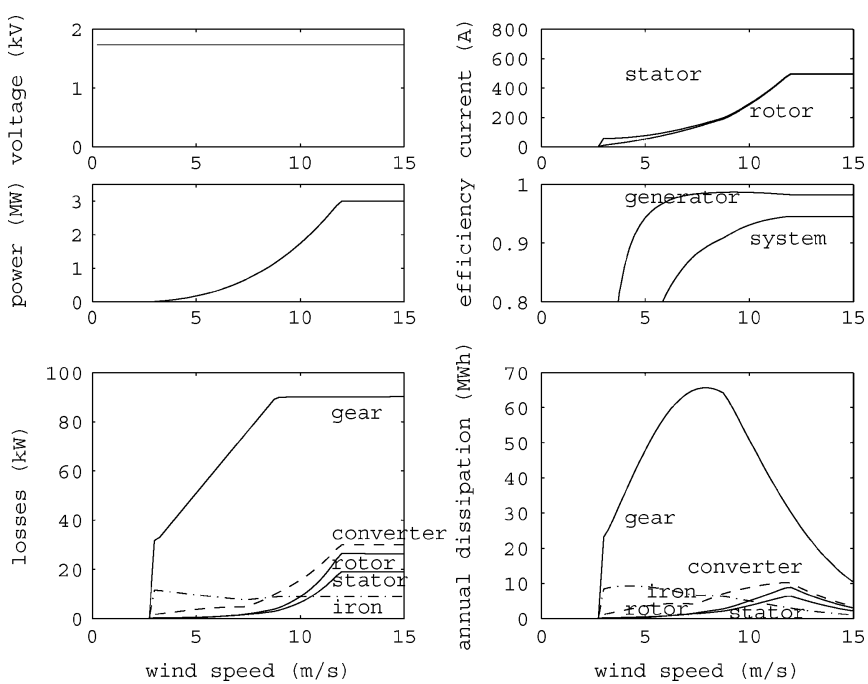

Fig. 6. Characteristics of the DFIG3G.

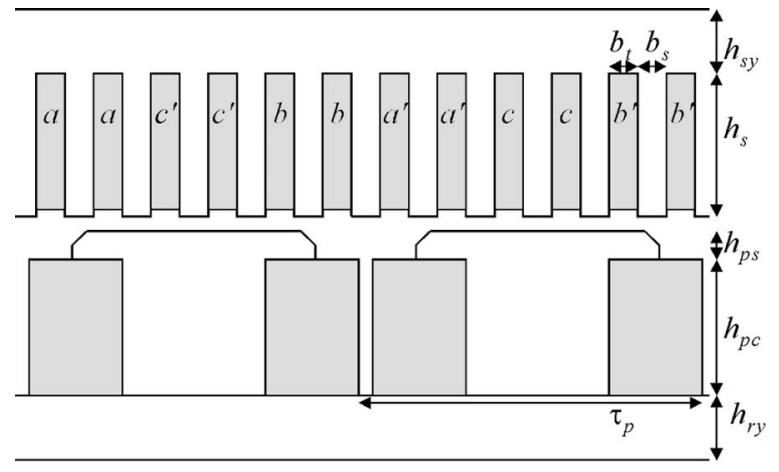

Fig. 7. Sketch of a linearized cross section of two poles of an electrically excited synchronous machine.

become more difficult. This 5-m air-gap diameter is a compromise between these criteria.

Fig. 7 depicts a cross section of two poles of the machine. The number of slots per pole per phase is two. Increasing this number makes the machine heavier and more expensive because of the increasing dimensions of end-windings and yokes. Decreasing this number results in a significant increase in the excitation losses, mainly in part load. Table II gives some other important dimensions.

Fig. 8 depicts the equivalent circuit of the DDSG and the applied phasor diagram. The phase current leads the phase voltage a little in order to reduce saturation and excitation losses while a larger rating of the converter is not necessary. A more extensive description of the model for saturation is given in [17]. 

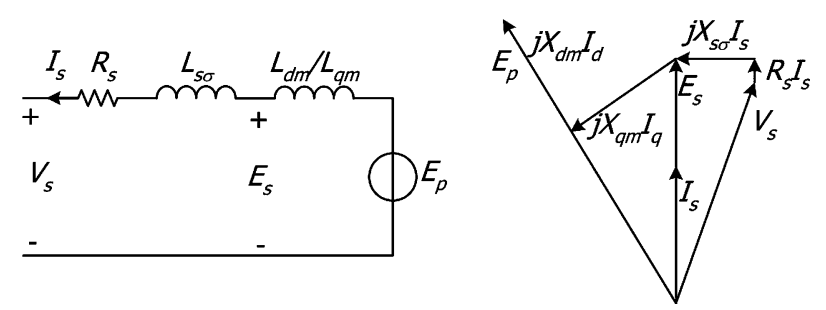

Fig. 8. Equivalent circuit of the DDSG and the applied phasor diagram.
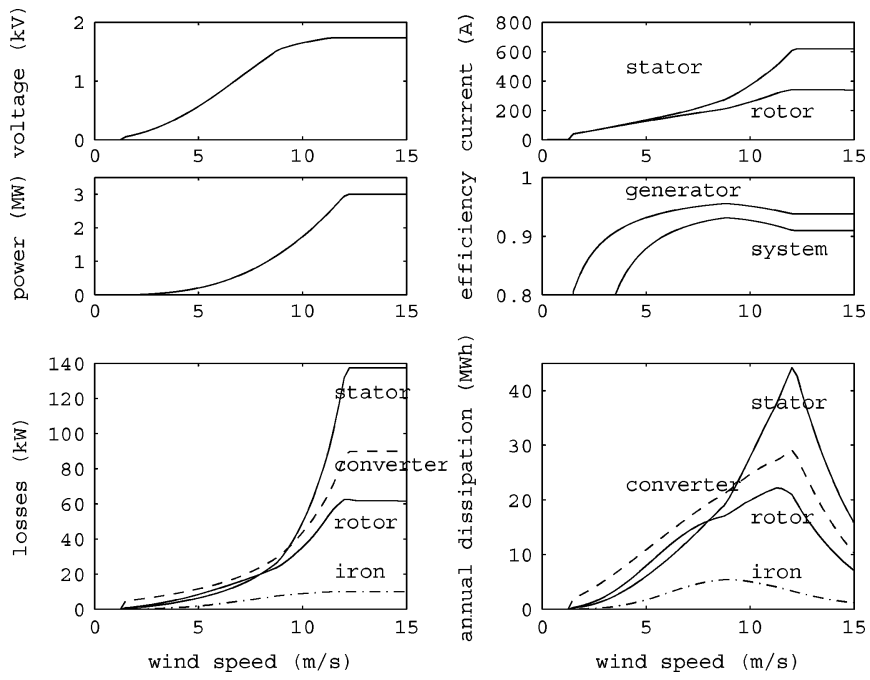

Fig. 9. Characteristics of the DDSG.

Fig. 9 depicts some results from the model as a function of the wind speed: voltage, current, power, generator efficiency, generator system efficiency (including losses in the converter), and losses. The annual energy dissipation, determined from a combination of the losses with the Weibull distribution is also depicted in Fig. 9. Table II gives the resulting annual energy yield and the annual dissipation. It also gives estimated costs. The generator construction is assumed to cost $€ 160000$.

The main sources of losses in this system are the copper losses in the stator and the rotor. They could be reduced by using more material, but that makes the generator more expensive. Iron losses are small; less than $5 \%$ of the annual dissipation in the system is in the iron. Using cheaper laminations with more losses will hardly influence the performance.

\section{DDPMG}

The air-gap diameter of the DDPMG is chosen as $5 \mathrm{~m}$ for the same reasons as for the DDSG.

A cross section of four pole pitches is depicted in Fig. 4. Compared to the DDSG the number of poles is doubled to reduce the risk of demagnetizing the magnets and to reduce the dimensions of yokes and end-windings. Doubling the number of poles does not increase the excitation losses as in the DDSG because permanent magnets are used. Other important dimensions are given in Table II.

The equivalent circuit of the permanent-magnet generator and the applied phasor diagram are depicted in Fig. 10. The phase
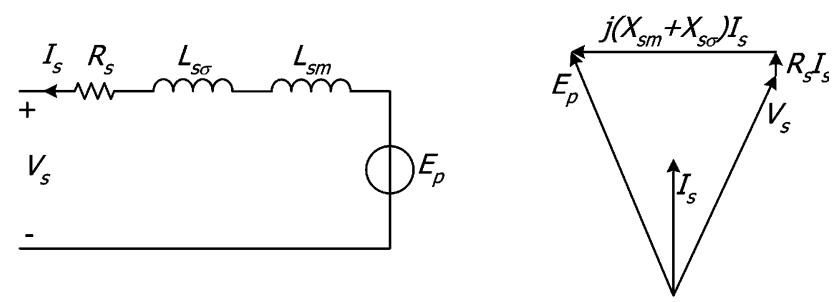

Fig. 10. Equivalent circuit of the permanent-magnet synchronous machine and the applied phasor diagram.
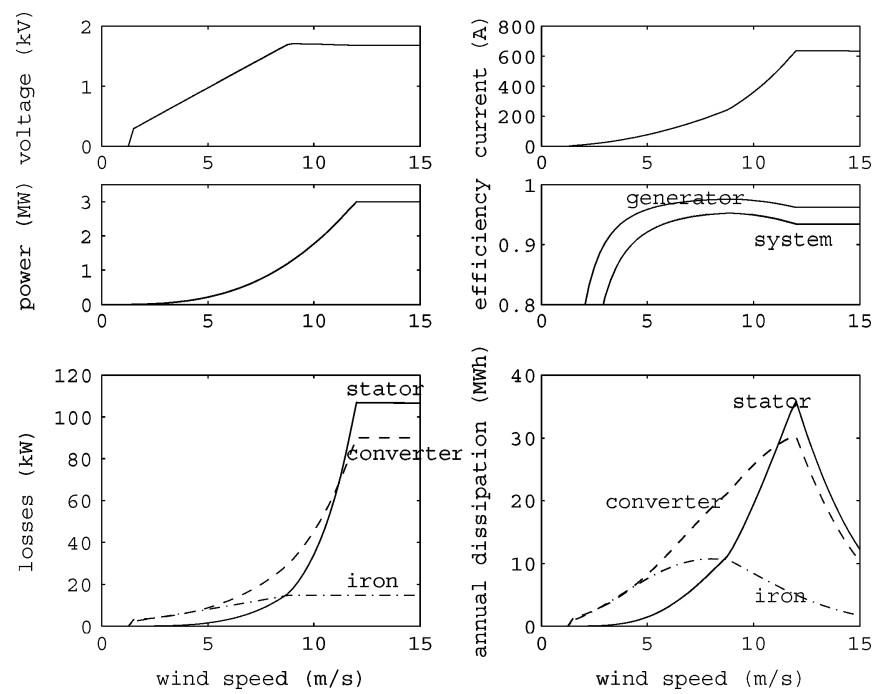

Fig. 11. Characteristics of the DDPMG.

current is in the middle between the terminal voltage and the voltage induced by the magnets in order to reduce the saturation and to get a compromise between the converter rating and the generator rating.

Fig. 11 depicts some results from the model as a function of the wind speed: voltage, current, power, generator efficiency, generator system efficiency (including losses in the converter), and losses. The annual energy dissipation, determined from a combination of the losses with the Weibull distribution, is also depicted in Fig. 11. Table II gives the annual energy yield, the annual dissipation, and the estimated costs. The generator construction is assumed to cost $€ 150000$, which is a little less than the construction of the electrically excited generator because the generator is lighter.

The largest part of the losses is losses in the converter. Iron losses are not negligible; at wind speeds up to $8 \mathrm{~m} / \mathrm{s}$, they are larger than the copper losses and over $15 \%$ of the annual dissipation in the generator system is in the iron.

\section{D. $P M G 1 G$}

Although the speed of the PMG1G generator is considerably higher than that of a direct-drive generator, the rated speed of 90 $\mathrm{r} / \mathrm{min}$ is still low. Therefore, this generator is also built as a ring machine with a large radius. The air-gap diameter is chosen as $3.6 \mathrm{~m}$ to eliminate the most important transportation problems. 

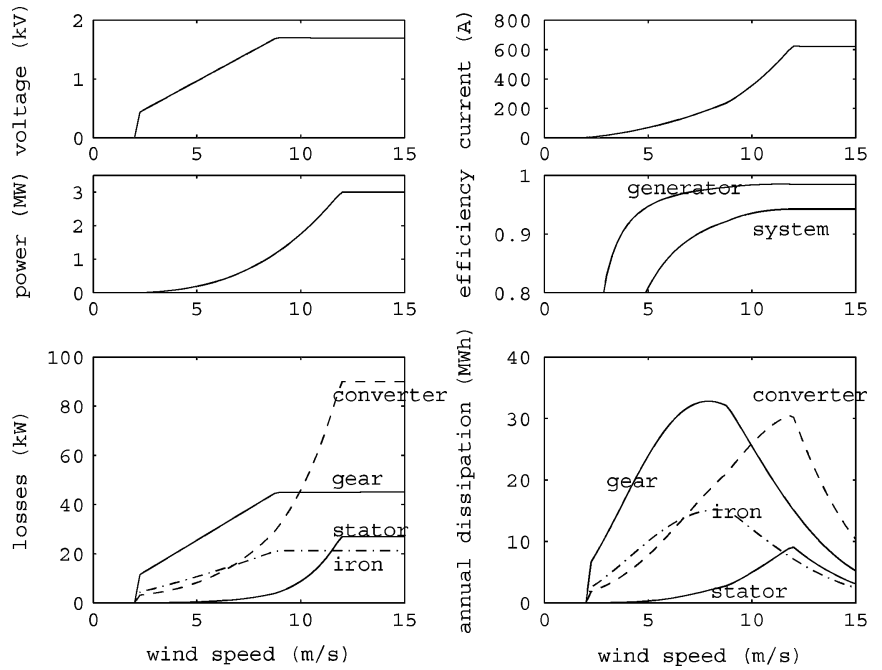

Fig. 12. Characteristics of the PMG1G.

The pole-pitch layout of this machine is kept the same as the pole-pitch layout of the DDPMG generator of Fig. 9. Other important dimensions are given in Table II. The control is kept the same as in Fig. 10.

Fig. 12 depicts some results from the model as a function of the wind speed: voltage, current, power, generator efficiency, generator system efficiency (including losses in the converter and the gearbox), and losses. The annual energy dissipation, determined from a combination of the losses with the Weibull distribution, is also depicted in Fig. 12. Table II gives the annual energy yield and the annual dissipation. It also gives cost estimates. The generator construction is assumed to cost $€ 50000$.

In this system, the losses in the converter and the gearbox are important. The iron losses in the generator at rated speed are in the same order of magnitude as copper losses due to the relatively high frequency of $84 \mathrm{~Hz}$.

\section{E. DFIGIG}

For the same reasons as for the PMG1G, the air-gap diameter of the DFIG1G is $3.6 \mathrm{~m}$. The rated speed of the DFIG1G is $90 \mathrm{rpm}$.

The rated speed of the induction machine with single-stage gearbox is $90 \mathrm{r} / \mathrm{min}$. The synchronous speed of the induction generator is chosen at $75 \mathrm{r} / \mathrm{min}$, so that at the rated speed, there is still some margin both in speed and power for control purposes. Because the stator is directly connected to the $50-\mathrm{Hz}$ grid, this means that the number of pole pairs is 40 .

This only leaves space for two slots per pole per phase, both in the stator and the rotor. In a squirrel-cage induction generator, this would lead to large additional losses, but in a wound-rotor induction generator, this should be acceptable.

The magnetizing current of this induction machine is rather large due to the considerable air gap and the high number of pole pairs. To reduce the magnetizing current to acceptable levels, the slots are semiclosed and the air gap is made $2 \mathrm{~mm}$, which requires a high rigidity of the bearing(s) and the supporting structures. Other dimensions are given in Table II.
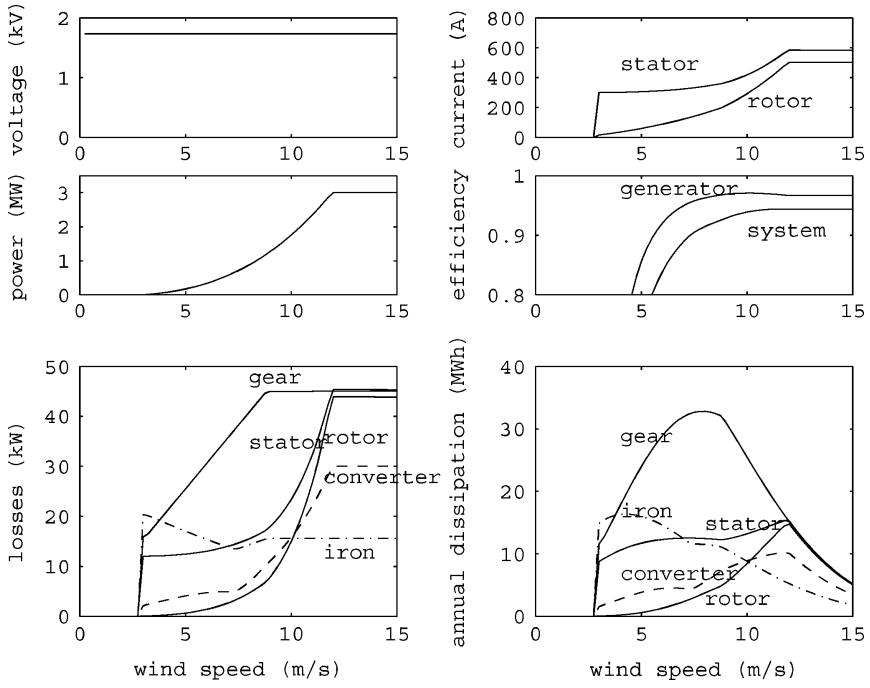

Fig. 13. Characteristics of the DFIG1G.

The DFIG1G is controlled in the same way as the DFIG3G.

Fig. 13 depicts some results from the model as a function of the wind speed: voltage, current, power, generator efficiency, generator system efficiency (including losses in the converter and the gearbox), and losses. The annual energy dissipation, determined from a combination of the losses with the Weibull distribution, is also depicted in Fig. 13. Table II gives the annual energy yield and the annual dissipation. It also gives cost estimates. The generator construction is assumed to cost $€ 60000$, which is $20 \%$ more than the generator construction of the singlestage GPM generator, because the generator is heavier and has a smaller air gap.

\section{COMPARISON AND DISCUSSION}

The DFIG3G is the lightest, low cost solution with standard components, explaining why it is most widely-used commercially. However, it has a low energy yield due to the high losses in the gearbox. Because it is mainly built from standard components consisting of copper and iron, major improvements in performance or cost reductions cannot be expected.

The DDSG appears to be the heaviest, and most expensive alternative. The only commercially successful large direct-drive wind turbine manufacturer, Enercon, uses this system but they claim other benefits from the system.

The DDPMG generator seems much more attractive because the active material weight of the generator for the same air-gap diameter is nearly halved, while the energy yield is a few percent higher. It has the highest energy yield. However, compared to the generator systems with gearbox, it is more expensive. Further improvements of this generator system may be expected because the cost of the permanent magnets and the power electronics is decreasing and because further optimization and integration of the generator system is possible [3], [18], [19].

The GPM1G is an interesting option, especially if this machine can also be used in other applications (for example, for ship propulsion) so that the development cost can be shared. 


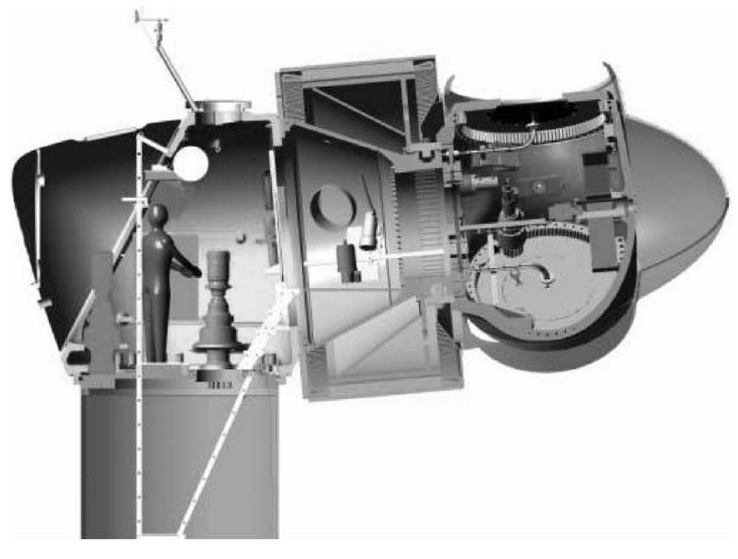

Fig. 14. Sketch of a Zephyros nacelle with a single bearing. Source: Zephyros BV.

Surprisingly, the DFIG1G seems the most interesting choice in terms of energy yield divided by cost. This is mainly due to the lower rating of the converter, resulting in a reduction of the converter cost and the converter losses. However, this system may be too special to be attractive for manufacturers.

Very important design aspects for which further work is needed are reliability and availability [20]. These are increasingly important issues for wind turbines, especially for the offshore ones. Manufacturers supplying the DFIG3G use generator and converter components which are close to industrial standards yielding benefits in standardization, cost, and reliability. However, this system has wearing components as the gearbox and the brushes. The DDSG with electrical excitation used by Enercon claims improved reliability including immunity to problems from voltage disturbances due to grid faults as a result of the use of a fully rated converter. In principle, the DDPMG could be the best solution because it does not have brushes or a gearbox that wears and it has the advantages of a fully rated converter.

Another aspect that has not been considered in this paper is that of integral design. An integral design of the turbine and the generator system including manufacturing, transportation, and installation may considerably affect the price of a wind turbine. Fig. 14 depicts an example of a nacelle where attention has been paid to the integration of the electromagnetic, mechanical, and thermal functions in the design [8].

\section{REFERENCES}

[1] J. G. Slootweg and E.de Vries, "Inside wind turbines-fixed vs. variable speed," Renew. Energy World, vol. 6, no. 1, pp. 30-40, Jan.-Feb. 2003.

[2] H. Polinder, S. W. H. de Haan, J. G. Slootweg, and M. R. Dubois, "Basic operation principles and electrical conversion systems of wind turbines," EPE J., vol. 15, no. 4, pp. 43-50, Dec. 2005.

[3] M. R. Dubois, "Optimized permanent magnet generator topologies for direct-drive wind turbines" Ph.D. dissertation, Delft Univ. Technol., Delft, The Netherlands, 2004.

[4] A. Grauers, "Design of direct-driven permanent-magnet generators for wind turbines" Ph.D. dissertation, Chalmers Univ. Technol., Göteburg, Sweden, 1996.

[5] E. Spooner, P. Gordon, J. R. Bumby, and C. D. French, "Lightweight ironless-stator PM generators for direct-drive wind turbines," Inst. Electr. Eng. Proc. Elect. Power Appl., vol. 152, no. 1, pp. 17-26, Jan. 2005.
[6] R. Poore and T. Lettenmaier. (2003). Alternative design studyreport: WindPACT advanced wind turbine drive train designs study. NREL, Golden, CO, Rep. Number NREL/SR-500-33196, 2003, Available: http://www.nrel.gov/docs/fy03osti/33196.pdf

[7] G. Bywaters, V. John, J. Lynch, P. Mattila, G. Norton, J. Stowell, M. Salata, O. Labath, A. Chertok, and D. Hablanian. (2004). Northern Power Systems WindPACT drive train alternative design study report. NREL, Golden, CO, Rep. Number NREL/SR-500-35524, 2004, Available: http://www.nrel.gov/docs/fy03osti/33196.pdf

[8] C. Versteegh, "Design of the Zephyros Z72 wind turbine with emphasis on the direct drive PM generator," presented at the Nordic Workshop on Power and Industrial Electronics (NORPIE), Trondheim, Jun. 14-16, 2004, Paper Number 68.

[9] A. Grauers, "Efficiency of three wind energy generating systems," IEEE Trans. Energy Convers., vol. 11, no. 3, pp. 650-657, Sep. 1996.

[10] R. Harrison, E. Hau, and H. Snel, Large Wind Turbines: Design and Economics. Chichester, U.K.: Wiley, 2000.

[11] J. R. Cotrell, "A preliminary evaluation of a multiple-generator drivetrain configuration for wind turbines," in Proc. 21 st ASME Wind Energy Symp., 2002, pp. 345-352.

[12] L. Helle and S. Munk-Nielsen, "Comparison of converter efficiency in large variable speed wind turbines," in Proc. 16th Annu. IEEE APEC Conf., 2001, vol. 1, pp. 628-634.

[13] N. Mohan, T. M. Undeland, and W. P. Robbins, Power Electronics: Converters, Applications and Design, 3rd ed. New York: Wiley, 2003.

[14] R. Richter, Elektrische Maschinen, Erster Band, 3rd ed. Basel: Birkhaüser, 1967.

[15] G. R. Slemon, Electric Machines and Drives. $\quad$ Reading, MA: AddisonWesley, 1992.

[16] H. Polinder, M. E. C. Damen, and F. Gardner, "Design, modelling and test results of the AWS PM linear generator," Eur. Trans. Elect. Power, vol. 15 , pp. 245-256, 2005.

[17] H. Polinder and J. G. Slootweg, "Design optimization of a synchronous generator for a direct-drive wind turbine," in Proc. Eur. Wind Energy Conf. Exhibition, Copenhagen, Jul. 2-6, 2001, pp. 1067-1070.

[18] A. Grauers and P. Kasinathan, "Force density limits in low-speed PM machines due to temperature and reactance," IEEE Trans. Energy Convers., vol. 19, no. 3, pp. 518-525, Sep. 2004.

[19] A. Grauers, P. Kasinathan, and E. S. Hamdi, "Force density limits in lowspeed permanent magnet machines due saturation," IEEE Trans. Energy Convers., vol. 20, no. 1, pp. 37-44, Mar. 2005.

[20] P. J. Tavner and J. Xiang, "Wind turbine reliability, how does it compare with other embedded generation sources," in Proc. IEE Rel. Transmission Distrib. Netw. Conf., London, U.K., Feb. 2005, pp. 243-248.

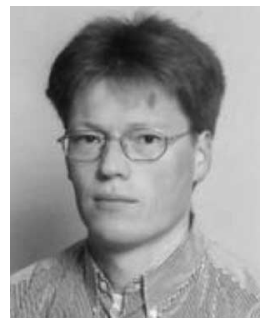

Henk Polinder (M'97) received the M.Sc. degree in electrical engineering and Ph.D. degree from Delft University of Technology, Delft, The Netherlands, in 1992 and 1998, respectively.

From 1996 to 2003, he was an Assistant Professor and since 2003, he has been an Associate Professor in the Electrical Power Processing Group Delft University of Technology. In 1998 and 1999, he worked part-time at the wind turbine manufacturer Lagerwey to design a direct-drive generator. He was a Visiting Professor at the University of Newcastle upon Tyne, U.K., in July and August 2002, and at Laval University, Quebec, Canada in July and August 2004. His current research interests include design aspects of electrical machines for renewable energy and mechatronic applications.

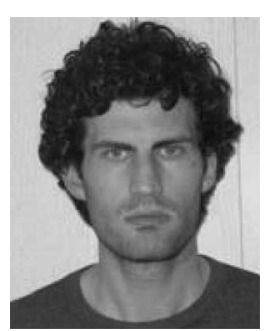

Frank F. A. van der Pijl received the M.Sc. degree in electrical engineering from Delft University of Technology, Delft, The Netherlands, in 2003. Currently, he is working toward the Ph.D. degree in the field of electrical power processing. 


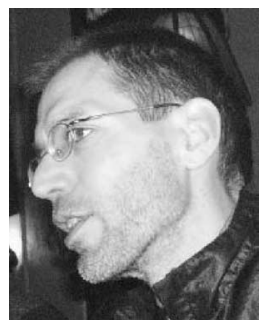

Gert-Jan de Vilder received the M.Sc. degree from the University of Wolverhampton, Wolverhampton, U.K. in 2002.

He has been involved in wind turbine design and wind turbine component design since 1985 working for various well established companies in wind energy. Among them are Lagerwey, NEG-Micon, Suzlon, and NedWind. Currently, he is with Harakosan Europe BV, NS Hilversum, The Netherlands.

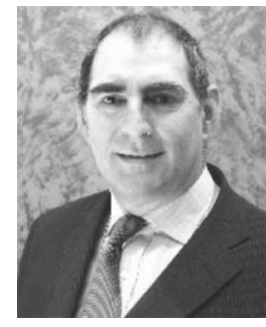

Peter J. Tavner received the M.A. degree in engineering sciences from Cambridge University, Cambridge, U.K., in 1969, and the Ph.D. degree from Southampton University, Southampton, U.K., in 1978.

Currently, he is a Professor of new and renewable energy at the School of Engineering, University of Durham, Durham, U.K. He has held a number of research and technical positions in the industry including those of the Technical Director of Laurence, Scott \& Electromotors Ltd., Norfolk, U.K. and Brush Electrical Machines Ltd., Loughborough, U.K. He was also the Group Technical Director of FKI-DeWind Energy Technology, Loughborough, U.K. His research interests include electrical machines for the extraction of energy from renewable sources and their connection to electricity systems, electromagnetic analysis, the application of condition monitoring to electrical systems, and the use of converters with electrical machines.

Dr. Tavner is a receipient of the Institution Premium Award of the Institutions of Electrical Engineers, U.K. 